\title{
Monitoring of Exhaust Gas Parameters of Stationary Combustion Systems In View of Environmental Standards
}

\begin{abstract}
K. T. Jayasinghe
Abstract: During the last few years, fossil fuel consumption for electricity generation and industrial process activities has gradually increased with the rapid development of energy and industrial sectors in Sri Lanka. When the fuel consumption increases, the relative quantities of emissions released to the environment too will increase. Such types of common emissions are toxic gases $\left(\mathrm{Pb}, \mathrm{Cl}_{2}\right)$, noxious gases $\left(\mathrm{SO}_{\mathrm{x}}, \mathrm{NO}_{\mathrm{x}}\right)$, green house gases $\left(\mathrm{CO}_{2}, \mathrm{O}_{3}\right)$, unburned gases $\left(\mathrm{CO}, \mathrm{C}_{\mathrm{x}} \mathrm{H}_{\mathrm{y}}\right)$, volatiles and respirable particles. Those emissions will harmfully affect, in different ways, the human health and the environment.
\end{abstract}

The regulatory bodies have actively monitored the industrial emissions by implementing \& amending old inactivated policies, regulations and standards. As a result of such implementaions, under the "Section 32 of National Environmental Act No. 47 of 1980" as amended by Acts 56 of 1988 and 53 of 2000 , the latest enviormnetal standard for emission regulations for staionary combustion systems has emerged.

In this regard, this paper aims to broadly discuss the experience gathered by the author in this area,in (view of) relation to? industrial impacts, instrumentations, pre facility requirement \& resource availability and external interferences. Further the recommendations made in this paper for individual combustion systems, such as, thermal power plants, standby generators, industrial boilers \& thermic fluid heaters, incinerators and cupola furnances, kilns etc. might be helpful to the regulatory bodies, industries, instruments \& equipment suppliers and monitoring organizations in different ways when introducing (introduce) those emission standards to the industries.

Finally, the outcomes of this study will help not only the local industries, but also Asian regional countries which have been operating similar combustion systems, to upgrade their systems to comply with particular environmental standards, because the proposed local standards have been prepared based on the other Asian and Europian regions' environmental standards.

\section{Keywords: Particulate Matter, Smoke Opacity, Isokinectic, Ringelman, Transmissivity, Themic Fluid}

\section{Introduction:}

Sri Lankan Statistics reveal that the industrial growth and electricity generation had increased by $11.0 \%$ and $7.9 \%$ respectively in 2010 [SEA Annual Report 2010]. It is expected that the industrial growth and electricity generation will further increase in the coming years due to the introducion of new development projects and rapid increase in electricity demand island wide. According to the current statistics, electricity generation heavily depends on the thermal power plants and in 2010 around $60 \%$ of the total generation had been shared by thermal power plants [SEA Annual Report 2010]. The main energy sources used in thermal power plants are fossil fuels and coal. In addition to that few bio fuel in-house electricity generation facilities have been operated especially in process industries such as activated Carbon production, rice processing, Sugar industries etc.

Industrial development also contributes to the exponential increase of fossil fuel consumption to obtain required thermal and electrical energy.

The common systems practices are steam \& hot water boilers, thermic heaters, diesel electricity generators etc. In addition to those electrical and thermal energy generating systems, a remarkable number of different types of stationary combustion systems such

Eng. K T Jayasinghe, CEng., MSc (Energy), MIE(Sri Lanka), Research Fellow, National Engineering Research \& Development Centre (NERDC), 2P/17B, Industrial Estate, Ekala, Ja-Ela. Sri Lanka. 
as incinerators, crematoria, cupolas, kilns, furnaces etc. are in operation island wide.

Out of those, many plants are out dated and they are operated under very low efficiency levels.

Setting up of unplanned and inefficient combustion systems will increase the pollution gases and contaminants emitted to the atmosphere. The common emissions released to the atmosphere are toxic gases $\left(\mathrm{Pb}, \mathrm{Cl}_{2}\right)$, noxious gases $\left(\mathrm{SO}_{\mathrm{x}}, \mathrm{NO} \mathrm{x}\right)$, green house gases $\left(\mathrm{CO}_{2}, \mathrm{O}_{3}\right)$, unburned compounds $\left(\mathrm{CO}, \mathrm{C}_{\mathrm{X}} \mathrm{H}_{\mathrm{Y}}\right)$, Suspended Particles (SP) and respirable particles etc.

Different kinds of emissions in small and medium processing plants such as boilers, thermic heaters, incinerators etc. are rather difficult to control than the emmisions in centralized large processing plants in thermal power generation, co generation, cement processing etc. In this context, adverse effects from small and medium stationary combustion systems to the environment might be high.

Even though the environmental policies have been introduced since Colonial times, policies related to emission from stationary combustion systems had not been strictly practiced by responsible parties. However, the regulatory bodies have been actively involved, in the last few decades, to implement such regulations aiming to control environmental emissions from stationary combustion systems.

In fact, this paper is not going to discuss the policy implementations or regulation practices by different organizations to monitor the environmental pollutions of stationary combustion systems. However, it broadly discusses the experience gathered by the author; under different types of stationary combustion systems, with respect to industrial impacts, instrumentations, pre facility requirement etc.

\section{Review of Emission Standards of Combustion Systems in Sri Lanka}

The implemented emission standards of stationary combustion systems have mainly focused on three major areas such as source categorizations \& measuring parameters, measuring regulations \& techniques, and system requirements.

\subsection{Source Categorizations \& Measuring Parameters}

According to the type of plants available in the country, stationary combustion systems have been divided in to 5 categories such as thermal power plants, boilers, thermic fluid heaters, incinerators, and cupolas, furnaces, ovens, kilns etc. The recommended monitoring parameters and emission levels of each category depend on the plant capacity and fuel used. The recommended monitoring parameters of different combustion sources are summarized in Table 1.

Table 1 - Summarized Monitoring Parameters of Stationary Combustion Systems

\begin{tabular}{|c|c|c|c|c|c|c|c|c|c|}
\hline Plant Category & 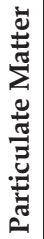 & 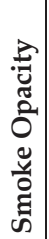 & ๑ே & $\stackrel{\swarrow}{\text { Z }}$ & ○ & $\underset{U}{\tilde{I}}$ & 000 & ㅇ & 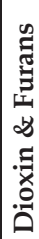 \\
\hline $\begin{array}{l}\text { Thermal Power Plants- } \\
\text { Any Fuel Except Solid } \\
\text { Waste }\end{array}$ & $x$ & $X$ & $x$ & $x$ & - & - & - & - & - \\
\hline $\begin{array}{l}\text { Thermal Power Plants - } \\
\text { Solid Waste Fuel }\end{array}$ & $x$ & $X$ & $x$ & $x$ & $x$ & $x$ & $x$ & $x$ & - \\
\hline Boilers & $X$ & $X$ & $X$ & $X$ & - & - & - & - & - \\
\hline Thermic Fluid Heaters & $x$ & $x$ & $x$ & $x$ & - & - & - & - & - \\
\hline Incinerators & $x$ & $x$ & $x$ & $X$ & $x$ & $x$ & $x$ & $x$ & $x$ \\
\hline $\begin{array}{ll}\text { Cupolas, } & \text { Furnaces, } \\
\text { Ovens, Kilns } & \\
\end{array}$ & $x$ & $X$ & $x$ & $X$ & - & - & - & - & - \\
\hline
\end{tabular}

According to Table 1 the common monitoring parameters of each combustion system are Particulate Matters (PM), Smoke Opacity, Oxides of Sulfur (SOx) and Oxides of Nitrogen $\left(\mathrm{NO}_{\mathrm{x}}\right)$. In additions to these common parameters, thermal power plants driven by solid wastes and waste combustion incinerators require to monitor $\mathrm{CO}, \mathrm{HCl}, \mathrm{Hg}$, $\mathrm{Pb}$ and Dioxin \& Furans. The recommended emission levels of each substance are not discussed in this paper. [Reference: - Section 32.0 of National Environmental Act. No 47.0 of 1980 for the recommended values].

\section{$2.2 \quad$ Measuring Regulations \& Techniques}

The emission monitoring methods described in this standard are based on the standard conditions, and the monitoring parameters are 
estimated based on the reference levels in order to bring the monitoring parameters by different organizations to a common standard format.

Based on the regulations, the emission parameters shall be,

- Monitored by instrument/ equipment based

- Converted in to dry basis \& normal condition $\left(0{ }^{\circ} \mathrm{C}\right.$ and $\left.760 \mathrm{~mm} \mathrm{Hg}\right)$

- Corrected for relevant reference Oxygen level. [Schedule 1 of National Environmental Act. No 47 of 1980 for reference Oxygen levels].

However the detailed descriptions of equations, conversions and regulations are not included in this paper. [Reference: - Section 32 of National Environmental Act. No 47.0 of 1980 for details].

\subsection{System Requirements and Limitations}

System requirements of this standard are described in order to control the toxic gases; especially $\mathrm{SO}_{2}$ and $\mathrm{NO}$. The key factors discussed under the system requirements are;

- In any case, the stack (chimney) height shall not be less than $20 \mathrm{~m}$

- In case of power plants, $\mathrm{SO}_{2}$ shall be controlled by fuel quality and stack height, if $\mathrm{SO}_{2}$ emission levels are not specified in the standards.

- Dioxin and Furan emission from incinerators shall be controlled by maintaining temperature within $1100{ }^{\circ} \mathrm{C}$ to $1250{ }^{\circ} \mathrm{C}$ and $2-3$ seconds retention time in secondary chamber.

\section{Monitoring Methodologies and Techniques}

In-depth analysis of monitoring methodologies and techniques related to PM, Smoke Opacity, $\mathrm{SO}_{x}$ and $\mathrm{NO}_{x}$ are important, since all the combustion systems shall be required to monitor those emissions as common parameters. In general, two monitoring methodologies, instrument/equipment based and titration based, are available for gaseous emission estimations. However only the instrument/ equipment based methods are described in this paper, since the monitoring methods described in particular standards are based on the instrument / equipment method.

\subsection{Monitoring of Particulate Matters (PM)}

\subsubsection{Test Method and Instrumentation}

The common method used for stack PM monitoring is "In-stack Filtration Method". In this method, PM is withdrawn isokinetically from the source and collected on a glass fiber filter maintained at a temperature, as specified by applicable standards, or approved by particular application. The PM mass which includes any material that condenses at or above the filtration temperature is determined gravimetrically after the removal of uncombined water.

The basic components of standard PM monitoring sampling train are probe nozzle; probe extension, filter holder, barometer, Pitot tube, differential pressure gauge, condenser, metering system, vacuum pump and heating element. The common arrangement of the instrument train is illustrated in Figure 1.

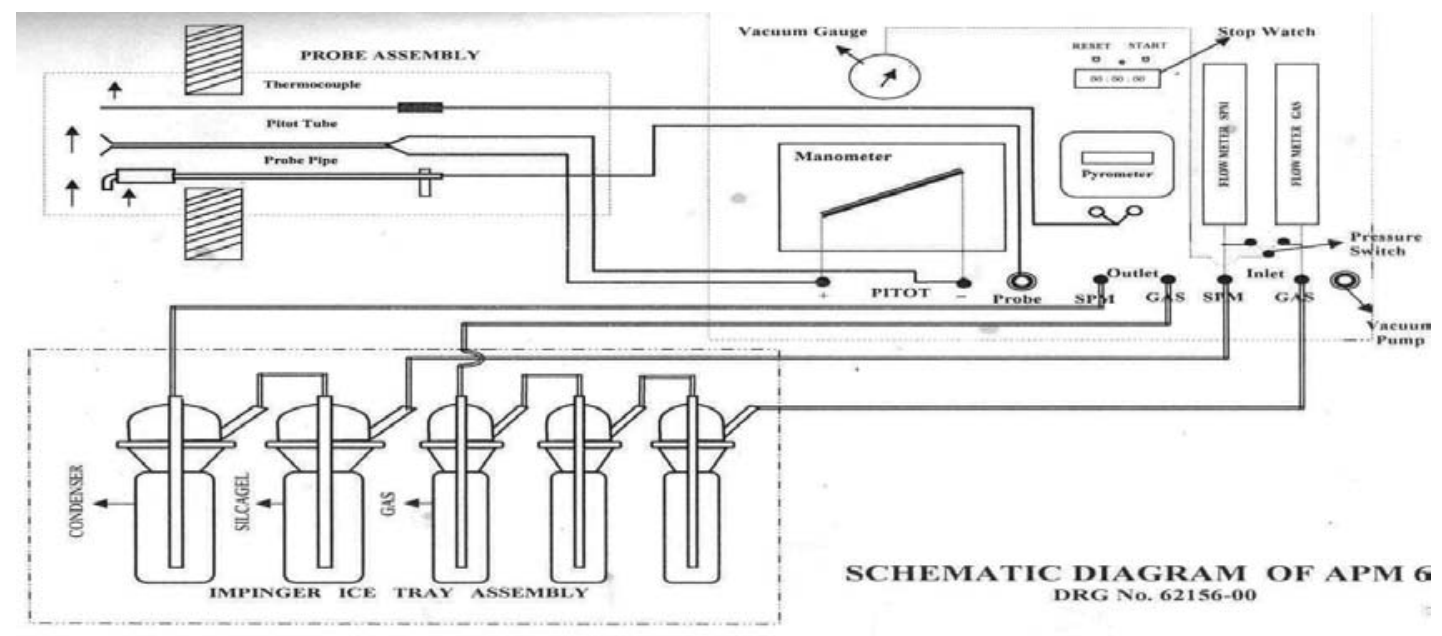

Figure 1 - Basic Components of PM Monitoring Sampling Train [Source-Envirotech 


\subsubsection{Applicability, Limitations and Facility Requirements for PM Monitoring}

The fundamental principle behind any sampling analysis is that a small amount of collected sample should be a representative of all the particles being monitored. Therefore variations in concentration, temperature or velocity across the duct, moisture, gas leakage or air infiltration can affect the measurements. Further the number of samples, monitoring locations and port sizes will depend on the homogeneity of the gas stream. Therefore for accurate measurements, it is required to follow the basic and standard methods. [Reference - BS EN 13284-1:2002 or any other acceptable standards]. According to the standards, PM sampling stations should be located at few meters above (depends on the stack arrangement) the ground level. Therefore it is important to facilitate a safe system set up for both operators and instruments. In this regard, a safe and permanent working platform and a lifting arrangement shall be required to reach the sampling locations. However, in exceptional circumstances; such as old plants or where the owner cannot bear the setting up facility cost (especially in small scale industries), temporary structures; scaffolding, mobile crane/lift etc. can be used. All the platforms, whether permanent of temporary, shall meet the standard dimensions, weight criteria, protection, facility requirements etc. [Reference - EN 13284-1:2002 or any other acceptable standards].

\subsection{Monitoring of Smoke Opacity}

Smoke Opacity is a property of a substance, especially unburned Carbon, which renders it partially or wholly obstructive to the transmission of visible light and it is expressed as the percentage to which the light is obstructed. [New Jersey Air pollution Control Act N.J.A.C. 26:2C-1]. Based on the standards [Ref. - Table 1.0], smoke opacity monitoring is common for any combustion system and shall be maintained below the recommended levels such as $10 \%, 15 \%, 20 \%$ etc.

Usually, two monitoring methods have widely been practiced to measure smoke opacity. Those are the "plume visual inspection method""Ringelmann" and the "Dual Beam Method".

\subsubsection{Test Methods, Instrumentations and} Limitations

\section{(a) Ringelmann Method:-}

Ringelmann Method is a visual assessment method and the darkness of smoke emitting at the top of the stack is compared with the standard shades of grey chart (called Ringelman) placed at a certain distance from the observer. The system arrangement is illustrated in Figure 2.

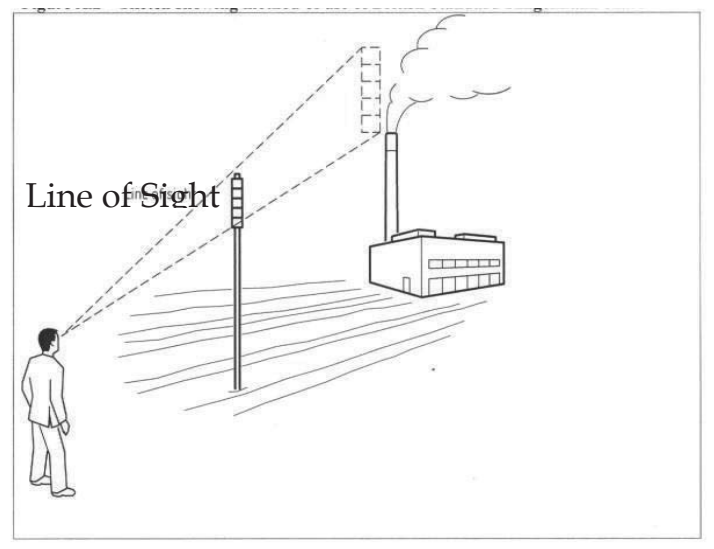

Figure 2 - Ringlemann Chart for Smoke Opacity Monitoring

\section{(b) Dual Beam Method}

Dual Beam Method is a universally accepted method to monitor smoke opacity. The basic principle of this method is to transmit a light beam through the flue gas (to be tested) and measure the reduction in its intensity.

Main components of the system are a twin beam transmitter, a high-intensity light source and detectors. The system arrangement is illustrated in Figure 3.

The main issue in this method is locating the monitoring system across the pre defined cross section of the stack at a certain height. [This height is defined to obtain a "Laminar Flow Region" and the level depends on the system set up]. Further, pre facility requirements to handle the instruments, to monitor/measure the parameters are not incorporated in many existing combustion systems. 


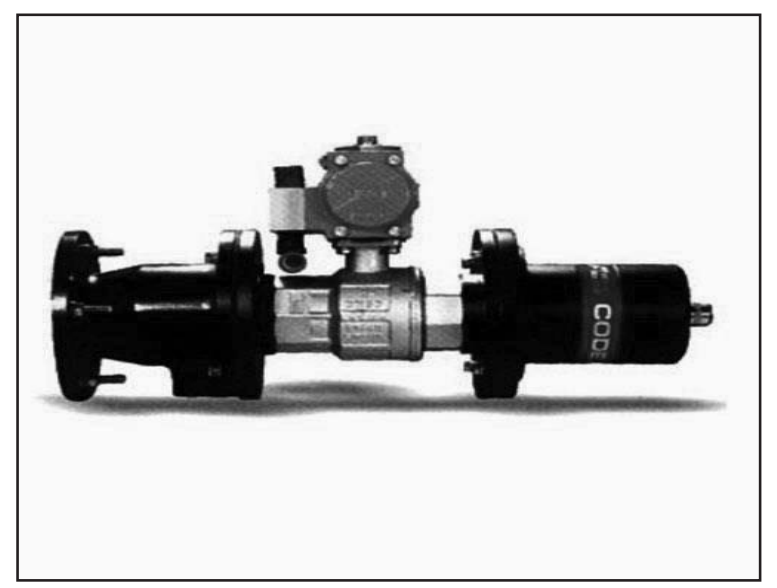

Figure 3 - Dual Beam Method Smoke Opacity Monitoring Kit [Source - Forbes Marshall DCEM 2100 - Unique Dual Beam Opacity/Dust Monitorl

\subsection{Monitoring of Dioxins and other Gaseous Components}

The most common gaseous emissions described in this particular standard are $\mathrm{SO}_{\mathrm{x}}$ \& $\mathrm{NO}$. However, in many cases, this standard has not described the marginal figures of $\mathrm{SO}_{\mathrm{x}}, \& \mathrm{NO}_{\mathrm{x}}$ and has advised to control those gaseous emissions by maintaining the stack height \& temperature by incorporating emission reduction utilities. In addition to that it is important to monitor $\mathrm{CO}, \mathrm{CO}_{2}$, excess air levels etc. in flue gas for efficient combustion systems.

\subsubsection{Test Methods, Instrumentations and Limitations}

In general, two methods of gaseous components determination, viz. extractive sampling method and non-extractive sampling method, have been practiced. Out of those two methods, extractive sampling method is the most common and widely used. In this method effluent gaseous samples are passed through the moisture and contaminant absorbent filters to remove the moisture (analysis under dry basis) and to clean the gas sample respectively before being conveyed to the instrument. Then the conditioned gas is passed through different chemical sensors (in built sensors) for necessary reactions. The composition of particular gaseous components are measured based on the number of electrons emitted by different chemical reactions. The common system arrangement is illustrated in Figure 4.

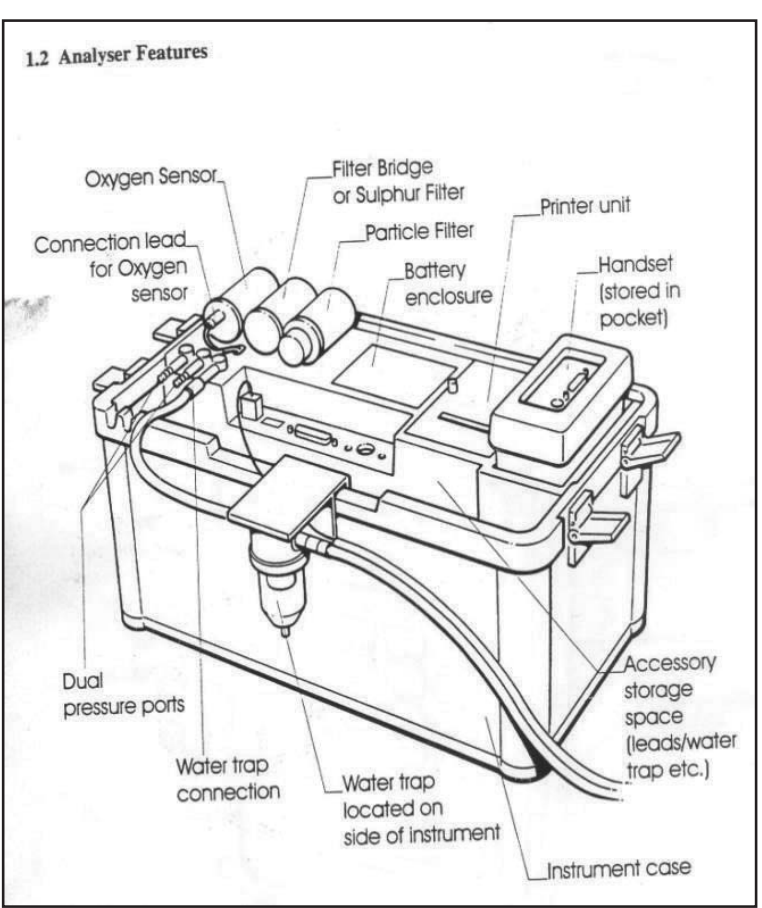

Figure 4 - Instruments for Exhaust Gas

The location of sampling points to monitor the gaseous concentrations is not critical like in monitoring PM. Because the variations of velocity profiles do not affect the homogeneity of the gaseous concentration. This means that the proximity to bends, branches, obstruction by fans and dampers are less important. But the sampling after dilution air must be avoided. Therefore monitoring of gaseous parameters is convenient and can be commonly implemented in many types of combustion systems, since those do not require any special and expensive pre-facilities arrangement.

\section{Implementation Difficulties of New \& Proposed Environmental Standards}

Not only the plant owners or industries, but also regulatory bodies and monitoring parties have come across different issues and difficulties, while implementing such requirements. Few such important factors are discussed herein from the point of view of industries/plant owners, third parties and instrumentation. 


\subsection{Implementation Difficulties}

The implementation of environmental standards for small \& medium industries is rather difficult compared with these for large combustion systems due to the under mentioned reasons.

- New standard pre facility requirements such as platforms, sample points, safe ladders etc. cannot be introduced to the existing systems due to structural weakness, failures, corrosion, space availability etc.

- Low income industries cannot bear the high capital (expenses) to modify their existing combustion systems to meet standard requirements.

- Industries that periodically operate (i.e. 2-4 times per month); especially foundry, DG sets etc. will have to meet same standard requirements like other continuous operating plants.

- The systems that have been already purchased; especially the waste combustion incinerators, crematoria etc. have not incorporated with emission control devices and techniques such as dual chamber, wet scrubbers, standard retention time etc.

- The chimney height can not be extended; especially in DG sets, furnaces, kilns, cupola etc., to meet the standard requirement due to the existing system set up, space availability, plant performance, structural failures etc.

- Low graded fuel; especially fossil fuels having high moisture, unexpected foreign particles etc. can not be controlled by plant owners.

- Expensive monitoring charges due to the limited number of monitoring parties and their demand.

\subsection{Monitoring Difficulties in View of Third Parties}

Even though the combustion systems are incorporated with continuous monitoring facility or not, the third party inspection and recommendation reports are required to confirm whether the particular combustion systems comply with the environmental regulations and are operated below the standards emission levels. Such monitoring parties should be registered under the Central Environmental Authority.
Out of 47 numbers of registered licensees in CEA for the year 2012, only 12 parties; 5 government organizations and 7 private institutions, have been involved in environmental monitoring practices. However many of them are having capacities to monitor fugitive air quality but they do not have capacity to monitor combustion emission. Out of those 12 registered parties, only three government organizations are having capacity to monitor PM and gaseous emissions. However, no one has facility to monitor all the basic emission parameters highlighted in the standards.

Further the under mentioned difficulties are met by the monitoring parties while practicing the measurements.

- Personal safety

- Instrument protection \& safety, handling difficulties

- Interferences of modified devices, such as moisture and water vapor released by wet scrubbers/wet bottom etc.

- Repeatability due to uneven combustion [Variations of process demand during monitoring]

- Lack of knowledge under different combustion systems

- High expenses required to maintain accreditation laboratory.

\subsection{Monitoring Difficulties in View of Instrumentation}

As discussed under the section 3.0, it is understood that special instrumentations and skill operators' assistance are required to monitor the emission parameters. The instruments recommended for particular tests are uncommon and expensive. Further, some instruments and chemicals, like opacity meters, $\mathrm{SO}_{x} \& \mathrm{NO}$ x reagent, heavy metal detectors etc., are not locally available.

The emission monitoring instrumentations shall be subjected to an annual calibration for accurate and standard measurements. In this regard, the particular instruments shall be sent to the principal suppliers; most probably out of the country, for re calibration and it will take nearly 2-3 months. 
Sudden failures of instruments; such as malfunctioning, sensor failures, physical damages etc. will also affect the regular monitoring practices.

\section{Discussion and Recommendations}

Author has made the under mentioned recommendations through industrial experiences related to exhaust gas monitoring and existing plant behaviors of stationary combustion systems, such as large scale combustion systems, standby generators, industrial boilers \& thermic fluid heaters, incinerators and cupolas, furnaces, kilns etc.

\subsection{Large Scale Combustion Systems}

Almost all the large scale combustion systems have been incorporated with the particulate matter and effluent gas controlling mechanisms, such as bag filters, cyclone separators, wet scrubbers etc. and inbuilt continuous operating emissions gas monitoring systems. In addition to that pre facility requirements such as working platform, lifting arrangements, sampling ports etc. have also been made available for periodical monitoring purposes. Such an arrangement is illustrated in Figure 5.

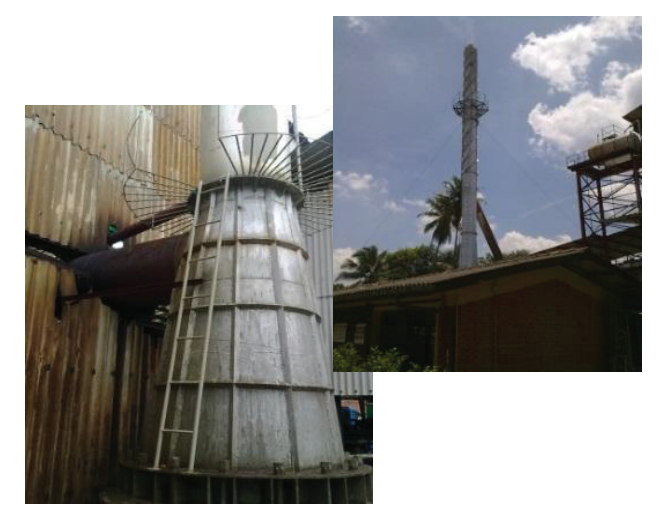

Figure 5 -Pre-Facility Requirements for Large Scale Combustion Systems

Therefore implementation of proposed standards for large scale combustion systems is practicable.

\subsection{Standby Generators}

The available standards guide to control PM, $\mathrm{SO}_{x} \& \mathrm{NO}$ emission of standby generators by maintaining a minimum $20 \mathrm{~m}$ stack height and fuel quality. Usually, standby generators are not incorporated with such type of taller stacks. Most of the standby generators are having only silencer with 6" - 8" diameter \& 1' - 5' length (depending on the capacity). Further it is practically impossible to extend or introduce a $20 \mathrm{~m}$ chimney to the standby generators, since such modifications will directly affect the plant performance. Typical arrangements are illustrated in Figure 6.

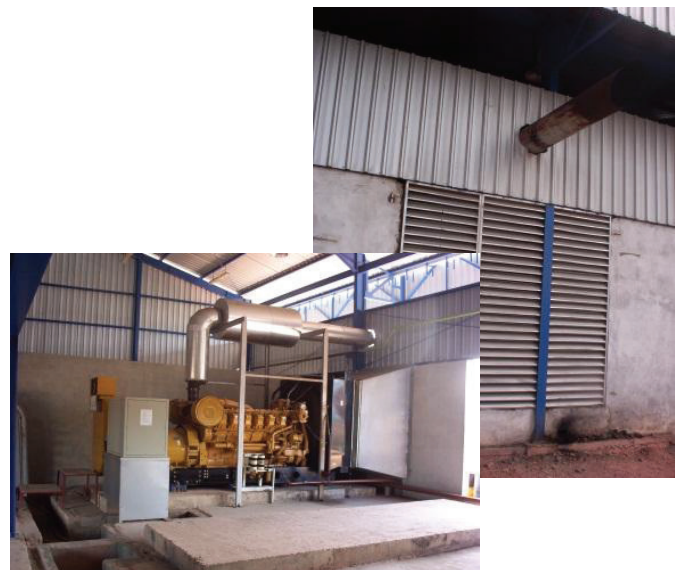

Figure 6 - Silencers in Standby Generators

In many industries, diesel generators have been used only for the emergency purposes (during the National power failures). Hence the emission released to the environment is comparatively less, because the average operating time and related fuel consumption are less. Therefore the impacts of gaseous emissions to the environment through standby generators are comparatively less.

Even though pre facilities are required to monitor PM (normally not available), instrumentations (Pitot tube, nozzle, filter holders etc.) do not match with such types of small stack diameters.

However it will not be a practical issue to monitor the opacity level using "Ringlemann" method in such types of shorter stacks. But monitoring of Opacity will also be an issue, if the stackheight increases up to $20 \mathrm{~m}$ [Ref. Sections 3.2.1]. 


\section{3}

Boilers and Thermic Fluid Heaters

Boilers and thermic fluid heaters are commonly used combustion systems in industries to obtain thermal energy demand. Almost all the combustion systems in these categories are incorporated with Mild Steel stacks having diameters ranging from 8 " to 24 " and height ranging from $5 \mathrm{~m}$ to $10 \mathrm{~m}$. Some stacks have been directly extended through the boiler house roof top and the others are extended by the branch connection between boiler and the stack. The arrangements are illustrated in Figure. 7.

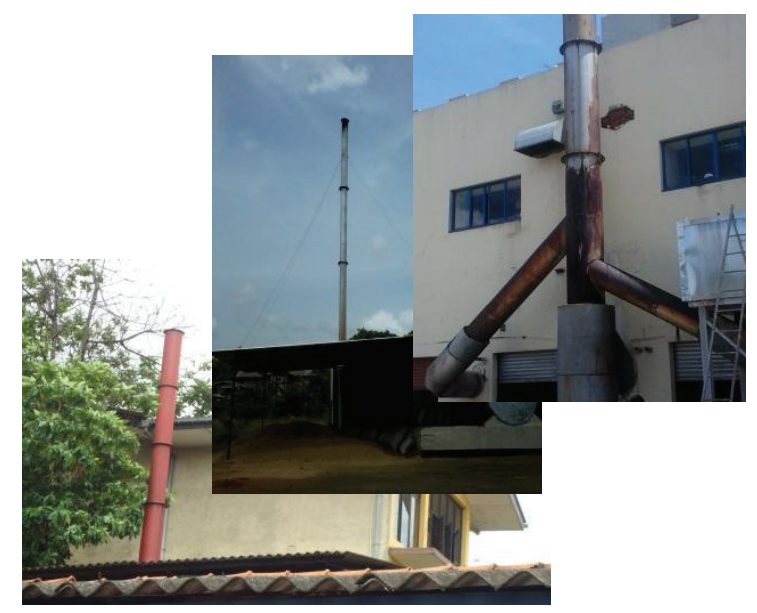

Figure 7 - Stack Arrangement of Boilers and Thermic Heaters

However in many stacks, it is practically impossible to extend the stacks to meet the standard requirements for gaseous emission controlling and to introduce pre facility requirements for PM monitoring. The main reasons found are structural failure, additional space requirements and effects to the draught etc. In addition to that the opacity monitoring by Ringelman method is not practical in many cases due to the similar issues discussed under Section 3.2.1.Therefore only solution to monitor exhaust gas emissions of boilers and thermic heaters is to introduce new stacks instead of the existing stacks to meet the standard requirements.

\subsection{Waste Combustion Incinerators}

Waste combustion incinerators are the worst stationary combustion systems among the different combustion systems discussed in this standard. Because, unlike the other combustion systems, not only the fuel combustion emissions, but other harmful gaseous substances from waste combustion also are emitted to the atmosphere. Therefore not only the $\mathrm{SO}_{\mathrm{x}}$ and $\mathrm{NO}_{x}$, the other toxic gases too have to be monitored in incinerators. [Ref.Table 1.0]. However many incinerators have not incorporated pre facility requirements to monitor either PM, opacity or any other gaseous parameters. Further the systems having water scrubbers and more than $20 \mathrm{~m}$ height stacks are rarely found.

Even through the emission regulations for waste combustion are stricter than for the other combustion systems, it can be seen that non standardized plants (emitting gaseous pollutants) are being operated island wide. This is basically due to non recommended waste combustion, over charging (waste), employing unskilled operators, mismatched plant specifications (stack height, retention time, number of burners etc.), and incineration temperature etc. The measurement and implementation issues discussed under section 5.3 are also applicable in this category of plants. In addition to that, some stacks are made out of fire bricks and therefore one cannot introduce monitoring pre facility and water scrubbing etc. The arrangement is illustrated in Figure 8.

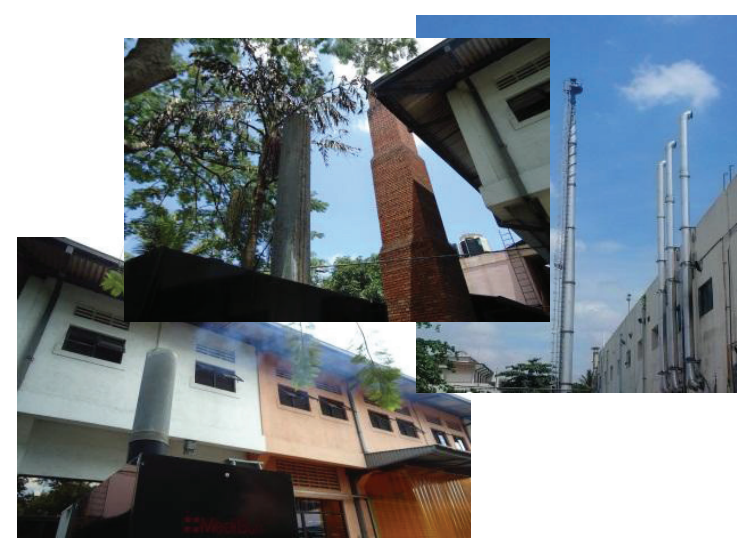

Figure 8 - Stack Arrangement of Incinerators

Further the instrumentations available to monitor $\mathrm{HCl}$, Mercury, Lead; Dioxin and Furans emission are hardy found.

This standard has also guided to monitor the secondary chamber temperature around $1,100^{\circ} \mathrm{C}$ $-1,250^{\circ} \mathrm{C}$ and the retention time is around 2-3 
seconds to control the Dioxins and Furans emissions. Out of those two monitoring parameters, the temperature can be monitored using high temperature sensors. But such type of sensors and instrumentations are not commonly available. In addition to that, there are no any practical methods to ensure that such plants operate under recommended/designed retention time.

Therefore while considering the above limitations, the most practical method to control emission from incinerators is to introduce a water scrubber to the system. However it is not practical to modify the existing incinerators due to unlimited number of design parameter variation. But permission can be given to purchase or set up new incinerators having water scrubbers, multi chambers, standard stack height etc.

\subsection{Cupolas, Furnaces, Ovens and Kilns}

The stack arrangements under this category of combustion systems are closely similar to the systems described under the sections 5.3 and 5.4. But the types and quantity of gaseous emissions depend on the fuel used, plants capacities, material process, and operating time. However some processes under this category are not continuous operations and those are operated once per week or fortnight or sometimes once a month.

Domestic level foundry industry belongs to this category. Many plants have been operated 3-5 hrsper day and 2-4 times per month. The fuels used for $\mathrm{Al}$ and $\mathrm{Cu}$ melting processes are burnt oil and for the cast iron melting process is coal. Like an incinerator not only the fuel combustion emissions, but also impurities of melting metals are mixed with the exhaust gases.

While considering the operating times per month, the quantity of metal processing and the amount of fuel combustion, it is not economical to introduce pre facility requirements or wet scrubbing systems to processing plants of such category. The arrangement is illustrated in Figure 9.

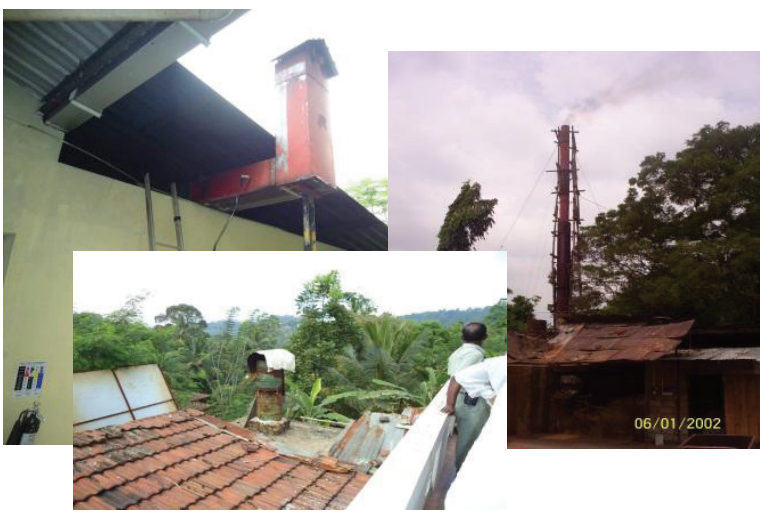

Figure 9 - Stack arrangement of Furnaces

However, out of the parameters mentioned in this standard;it is possible to practice the opacity test using "Ringlemann" method.

\subsection{Crematoria}

In this standard, it is described that the emission from crematoria shall be controlled by introducing emission control devices. Even though the particular controlling devices are not mentioned, it may be a water scrubber. But introducing water scrubber again might be an issue to release water with toxic contaminants to the environment. Therefore only possible solution for crematoria is to maintain chimney height according to the standards. Further in general, crematoria are single chamber combustion system. Therefore introducing a secondary burner (attached to the stack) to burn the exhaust toxic gases at higher temperature will help to reduce the Dioxin emission. Further it is not possible to implement any toxic gases or PM monitoring procedures during cremation due to cultural/traditional issues.

\section{Conclusion}

The outcomes of this paper will be useful to the regulatory bodies for updating the proposed emission standards in more practical, flexible, and convenient ways. For an example, requirement of separately categorizing the periodically operating plants and continuous operating plants, since the quantity of emission release to the environment are different. Further the contents of this paper will help industries to modify their existing systems according to the new standard, pre facility requirements etc. Also 
the techniques discussed under measurements will help monitoring parties to update their knowledge under the emission monitoring systems. Finally the author expect contribution from regulatory bodies, industries and monitoring parties to mitigate the environmental impacts by reducing emission release to the atmospherevia stationary combustion systems.

\section{Acknowledgement}

I would acknowledge Engineer D R Pulleperuma, the former Chairman, National Engineering Research \& Development Centre (NERDC) for providing his valuable input to make this paper a success. Further I take pleasure in thanking Engineer D D Ananda Namal, the Director General, NERDC, for granting permission to publish this paper. I also appreciate the comments made by the Director of the Renewable Energy Department Eng. Nandana Edirisinghe and Senior Research Scientist (Mrs.) Nayana Pathiraja, of NERDC, to make this paper a Success.

\section{References}

1. International Standards; ISO 10155 Stationary Source Emissions - Automated Monitoring of mass Concentrations of Particles - Performance Characteristics, Test methods and Specifications.

2. International Standards; ISO 7935 Stationary Source Emissions - Determinations of the Mass Concentration of Sulfur Dioxide - Performance Characteristics of Automated Measuring Methods.

3. International Standards; ISO 10396 - Stationary Source Emissions - Sampling for the Automated Determination of Gas Concentrations.

4. Technical Guide Not (Monitoring) M I Sampling Requirements for Stack Emission Monitoring; Environment Agency, Version 4, July 2006.

5. Technical Guide Note (Monitoring) M 2 Monitoring of Stack Emissions to Air; Environment Agency Version 4, July 2006.
6. Proposed Environmental Standards for Stationary Combustion Sources; Central Environmental Authority, Sri Lanka.

7. “KM 9106” Flue Gas Analyzer Operation Manual, Kane International Limited, Kane House, Swallowfield, Welweyn Garden City, Hertfordshire, AL 7 IJG.

8. "ENVIROTECH APM 621" Stack Monitoring Kit Operation Manual, VAYUBODHAN UPKARAN (Pvt.)Ltd. A 292/1, OkhlaIndustrial Area Phase 1, New Delhi - 110020.

9. Sri Lanka Environment Outlook 2009, Ministry of Environment \& Natural Resource, United Nations Environment Programme. 